7. If any of these difficulties arise, the College representative should recommend very strongly that the Appointments Committee should either delay its recommendations or else submit them to the employing Authority without informing the candidates. If this is not done, he should ask that his disagreement be minuted.

8. If action under 5 is to be undertaken, the College representative should tell the Appointments Committee what he proposes to do*. He should then send a copy of the minority report, giving full reasons for his opinion, and any further relevant observations, to the President of the College as soon as possible. This information will be regarded as strictly confidential.

9. College representatives are invited to keep the Registrar informed of any difficulty in interpreting these notes.

April 1986

*In Scotland National Panel Members are asked to apply these guidelines and in cases of difficulty should inform the Chairman of the Scottish Division before writing to the Secretary of State.

\title{
Appendix
}

\section{Criteria for Consultant Posts in Psychiatry}

1. Before appointment to a Consultant post, whether in general psychiatry or one of the other psychiatric specialties, a candidate must have undertaken a basic training in psychiatry and hold the MRCPsych or equivalent qualification. If there is an outstanding candidate, or circumstances are highly exceptional, other relevant qualifications and experience may constitute an acceptable alternative.

2. The successful candidate should normally have reached the age of 32, but there is no bar to the appointment of younger applicants.

3. Due weight should be attached to breadth of experience, participation in organised rotation schemes, periods spent abroad in relevant posts, and work in medical fields allied to psychiatry.

The view of the College is that the responsibilities of all Consultant posts include the function of training those in medical and related disciplines, so that some teaching experience and supervision of trainees is desirable in candidates for appointment as Consultant. Experience in research, especially if this has proved worthy of publication, will enhance a candidate's application. But even the most outstanding experience of this kind should not be allowed to override the essential requirements laid down in (1) above.

4. The Joint Committee on Higher Psychiatric Training (JCHPT) has decided not to institute an accreditation procedure at this stage. Senior Registrar or equivalent posts have, however, been inspected and the JCHPT urges College Assessors to ensure that candidates have been trained in such posts and that they are not normally apppointed to the consultant grade before completing at least three years of higher training. A proleptic appointment may be appropriate for candidates lacking in part of this experience (see p. 2, para 6). (The JCHPT's second report was published in 1980).
5. Specific requirements for various types of Consultant posts are as follows:

(a) General Psychiatry

Normally three years of recognised general professional training in psychiatry followed normally by at least three years of higher training in an approved training post. Exceptions may occasionally be made for outstanding candidates with other relevant experience (e.g. research or service overseas) but a minimum of five years training in psychiatry, including clinical research, is still required. Although part of the three year period of higher training can be spent working in any specialised field, at least one year must have been spent in general adult psychiatry.

(b) Child and Adolescent Psychiatry

Basic training in general psychiatry, which may also include time in a registrar post in child psychiatry, should have been followed by experience in all aspects of the speciality in a Senior Registrar training post, preferably for a period of three years.

\section{(c) Mental Subnormality (Mental Handicap)}

The basic training in general psychiatry should have been followed by experience in the practice of psychiatry with the mentally handicapped in different settings; this experience should preferably be in a Senior Registrar training post, normally for a period of three years, but experience in a related field should be given due weight.

For a joint appointment with general psychiatry, specialist training in mental handicap should be obtained at Senior Registrar level in a training scheme which can offer further experience in those aspects of mental handicap necessary to consultant psychiatric practice in this field. A candidate for a specialist post in mental handicap, be that post on a full-time, joint 
appointment, or special interest basis, should have held a Senior Registrar or equivalent academic post in such a training scheme normally for a period of three years.

For a joint appointment in child and adolescent psychiatry and mental subnormality the Senior Registrar training period should normally be for at least three years with specific experience in the psychiatry of mentally handicapped children in both hospital and community settings.

\section{(d) Forensic Psychiatry}

The basic training in general psychiatry should have been followed by experience in forensic psychiatry, in a Senior Registrar or equivalent training post, normally for a period of three years. Experience in a related field should be given due weight.

\section{(e) Psychotherapy}

The basic training in general psychiatry should have been followed by specialist training and experience for a period normally of three years in the practice of psychotherapy preferably in a Senior Registrar training post.

\section{(f) Psychiatry of Old Age}

Basic training in general psychiatry, which should have included training in the psychiatry of old age, should be followed by at least one year of experience in this field during the Higher Professional Training period.

(g) Consultants in General Psychiatry with a Special Interest in a Named Specialty

Posts are often advertised for consultants to work in general psychiatry with a 'special interest' in one of the following subjects-alcoholism and/or drug addiction; rehabilitation; the psychiatry of old age; liaison psychiatry; behavioural treatments; mental handicap; forensic psychiatry; psychotherapy; and adolescent psychiatry (child and adolescent psychiatry cannot, however, be a special interest subject for a general psychiatrist). Candidates for such posts need to have had substantial experience both in general psychiatry and in the special interest subject.

Candidates should also have spent at least one year of their higher training in a conventional general psychiatric post and, as in the case of other consultant posts, should have completed three years of higher training altogether. If an otherwise well qualified candidate has had insufficient experience of the special interest subject a proleptic appointment may be recommended, provided the Advisory Appointments Committee has an assurance that the candidate will be given the opportunity to acquire the requisite experience immediately after taking up the post (see p. 2, para 6).

\section{(h) Special Hospitals}

While most consultants in Special Hospitals will be fully trained forensic psychiatrists, those trained in general psychiatry or in mental handicap with a special interest in forensic psychiatry could well contribute to the work of a Special Hospital. The special interest in forensic psychiatry would be recognised in the terms already defined by the College, i.e. at least one year's experience in forensic psychiatry. However, it may be that a suitable candidate, trained in general psychiatry or mental deficiency, but without any, or enough experience in forensic psychiatry, and wishing to develop such an experience, could be offered a proleptic appointment by the Advisory Appointments Committee. He/she would be expected to acquire the necessary experience as soon as possible after taking up the appointment. On making such an appointment the need for the Special Hospital to have substantial consultant cover by forensic psychiatrists must be borne in mind.

\section{The Role, Responsibilities and Work of the Child and Adolescent Psychiatrist}

\section{Introduction}

This paper, produced by the Child and Adolescent Specialist Section of the Royal College of Psychiatrists, is a revised version of the document of the same title published in the Bulletin in 1978'.

Its purpose is to describe the role of the child and adolescent psychiatrist today. In what follows 'child psychiatrist' will generally be used to mean 'child and adolescent psychiatrist'.

\section{Training and appointment of a consultant child and/or adolescent poychiatrist}

A consultant child psychiatrist is a qualified medical practitioner. Following pre-registration and other house officer jobs, general professional training takes place, which is normally a three-year preparation for the examination for the Membership of the Royal College of Psychiatrists (MRCPsych), and in some cases a 